\title{
De Volta aos Primórdios: em defesa do SUS como uma política antiRracista ${ }^{1}$
}

Fernanda Lopes²

\section{ONDE SE SITUA O TEXTO}

Este texto não é investigativo, mas uma reflexão pessoal e subjetiva, na perspectiva dos direitos humanos, acerca do Sistema Único de Sáude (SUS) como instrumento de promoção da justiça social e equidade racial. Ao falar sobre o SUS, resgato seus princípios e diretrizes, perpasso a discussão sobre determinação social da saúde, dando destaque ao racismo como determinante social e à insuficiência das discussôes a respeito das desigualdades raciais em saúde, quando o desafio é a promoção da equidade racial. Longe de ser algo conclusivo, apresento algumas questóes que poderão ser utilizadas para avaliar se os esforços empreendidos são efetivos para mitigar os efeitos do racismo no setor.

\section{A SAÚDE COMO UM DIREITO HUMANO}

A saúde é resultado de um conjunto de condições individuais e coletivas influenciado por fatores, circunstâncias e contextos de ordem política, econômica, ambiental, cultural e social. Longe de serem fatalidade ou destino, a saúde e a doença são processos históricos e sociais determinados pelo modo como se vive, se organiza e se reproduz cada sociedade (Brasil, 2006, p. 589).

Os direitos humanos são garantias jurídicas inerentes à pessoa humana que protegem a liberdade e a dignidade; não fazem distinção; não podem ser transferidos, dispensados ou retirados. Têm igual valor, são interdependentes, indivisíveis e válidos tanto no âmbito individual quanto coletivo. De acordo com Fonteles (2016, p. 14), os direitos humanos são "indispensáveis para uma existência humana digna, como, por exemplo, a saúde, a liberdade, a igualdade, a moradia, a educação, a intimidade". O conteúdo dos direitos humanos vincula-se à condição humana, constitui-se uma exigência cuja satisfação é necessária para que um ser tenha seus direitos reconhecidos. Os direitos humanos não devem estar subordinados à moral, a uma hierarquia de normas; não constituem uma concessão da sociedade ou de agentes públicos; são internacionalmente garantidos, e estáo legalmente protegidos.

Como os demais direitos humanos, a saúde é um pré-requisito para a plena ação e liberdade individual. A capacidade de os indivíduos agirem de acordo com sua consciência, no que toca à sua própria saúde, está diretamente ligada às normas e valores específicos do meio social onde vivem, e às condiçóes de vida e saúde de suas famílias e comunidades. Neste sentido, a construção da saúde como um direito humano deixa de ter uma interpretaçáo individualista e passa a orientar o bem-estar dos grupos sociais, reafirmando a dignidade individual e coletiva como valor civilizatório.

No Brasil, quando os movimentos sociais conquistam sua inclusão na Constituição Federal de 1988 (CF/1988), a saúde passa a figurar como direito universal. De acordo com Brasil (1988, art. 196) "a saúde é um direito de todos e dever do Estado, garantido mediante políticas sociais

1. DOI: http://dx.doi.org/10.38116/bapi26art1

2. Doutora em saúde pública (área de epidemiologia). É pesquisadora independente, consultora especializada nas áreas de saúde e direitos humanos, desenvolvimento, equidade racial e de gênero, e membro do Grupo Temático Racismo e Saúde da Associação Brasileira de Saúde Coletiva. Atualmente, é diretora de programa do Fundo Baobá para Equidade Racial. 
e econômicas que visem à redução do risco de doença e de outros agravos e ao acesso universal e igualitário às açôes e serviços para sua promoção, proteção e recuperação". É no contexto dessa nova ordem social, focada na promoçáo do bem de todas as pessoas, sem preconceitos de origem, raça, sexo, cor, idade e quaisquer outras formas de discriminação (Brasil, 1988, art. 3o, inciso IV), que o SUS é criado (Lei Federal no 8.080, de 19 de setembro de 1990).

\section{DETERMINAÇÃO SOCIAL DA SAÚDE}

Quando de sua criação nos anos 1990, o movimento de saúde global desafiava o paradigma biomédico, desmascarava a ideia de que um melhor atendimento médico poderia gerar, por si só, grandes ganhos na saúde da população. O movimento defendia que, para que o estado de saúde da população tivesse uma melhora significativa, não era suficiente investir no atendimento clínico; este investimento deveria estar aliado a intervençôes ambiciosas em setores como educação, trabalho, emprego e renda, saneamento, habitação e bem-estar, com vistas, sobretudo, a reduzir as desigualdades entre privilegiados e desfavorecidos. Naquele momento o conceito de desigualdades em saúde passa a assumir maior relevância e centralidade na saúde coletiva - situação que se mantém na atualidade.

As estruturas de governança formais e informais, as políticas macroeconômicas (fiscais, monetárias, políticas de mercado e a estrutura do mercado laboral), sociais (emprego, posse de terra e habitaçáo; educação, saúde, água e saneamento, meio ambiente), redistributivas, de seguridade e proteção social, além dos aspectos relacionados com a cultura e valores sociais legitimados pela sociedade, como se sabe, influenciam as condiçóes de moradia, determinam características e dinâmicas dos territórios, modulam a participação no mercado e as condiçóes de trabalho, emprego e renda, bem como o acesso e a disponibilidade a alimentos, água, informação, educação, assistência social e saúde. Todos esses fatores correlacionados determinam estilos de vida, hábitos, atitudes e comportamentos em saúde; geram estressores psicossociais, circunstâncias estressantes e condiçóes desiguais de adoecimento, cuidado, tratamento, recuperaçáo ou morte.

Esse quadro complexo que a Organização Mundial da Saúde (OMS) intitula determinantes sociais, econômicos, ambientais e comportamentais da saúde assume posiçáo de grande relevância no modelo de determinantes sociais em saúde atualmente adotado pela instituição (Solar e Irwin, 2010). No entanto, para Garbois, Sodre e Dalbello-Araujo (2017), nas análises empreendidas com base neste modelo, há um hiato de conteúdo crítico, uma perda de conexão com o pensamento da medicina e da epidemiologia social latino-americana, fragilizando a saúde coletiva. Para os autores, os determinantes da saúde têm sido abordados simplesmente como "fatores", "contextos", "circunstâncias" e "condições", ofuscando, sobremaneira, o entendimento acerca das articulaçóes

entre os múltiplos processos socioeconômicos, culturais, ecobiológicos, psicológicos e suas influências no processo saúde-doença-cuidado-morte - opinião com a qual coaduno.

\section{O SUS, SEUS PRINCÍPIOS E DIRETRIZES}

Ao estabelecer que os beneficiários da saúde já não seriam apenas aqueles que contribuíam para a previdência social, em regra, pessoas com vínculo empregatício, então atendidas pelo Instituto Nacional de Assistência Médica da Previdência Social (Inamps), o Brasil cria um mecanismo de promoção de justiça social, o SUS. 
A nova política de Estado, instituída formalmente em 19 de setembro de 1990, por meio da Lei Federal no 8.080, foi estabelecida para garantir que a saúde se constituísse em um direito para todas as pessoas. Não por acaso seus princípios e diretrizes são universalidade, integralidade, equidade, descentralização e participação social: para todas as pessoas (universalidade); tudo o que tenha eficácia e resolutividade comprovadas por evidências científicas, quer seja no campo da promoção, proteção ou recuperação, em todos os níveis de complexidade (integralidade); com atenção particular para aqueles que têm mais necessidades e que estáo às margens do poder (equidade); organizada de modo a respeitar dinâmicas e autonomia locais (descentralização); e sem negar a autoridade central e seu caráter de unicidade, e com intensa participação da comunidade (participação social).

A universalidade, ao mesmo tempo que constitui uma diretriz, é o que deve definir toda a base administrativa da saúde, dado que o acesso universal é entendido como a ausência de barreiras econômicas, organizacionais, geográficas e socioculturais no que tange aos cuidados da saúde. O recrudescimento da crise social e política, associado às mais de 135 mil vidas ceifadas pela crise sanitária agudizada pela pandemia da Covid-19, pressupóe a defesa da Seguridade Social. Medidas implementadas no contexto da emergência são necessárias, mas não suficientes. É preciso aprimorar e manter as políticas de transferência de renda preexistentes. Para a Abrasco (2020c), algumas das medidas imediatas que nos permitirão ampliar os gastos e enfrentar as crises em suas múltiplas dimensôes incluem a extinção da Desvinculação das Receitas da União (DRU), que retira 30\% dos recursos destinados ao financiamento da Seguridade Social, e a revogação da Emenda Constitucional no 95/2016, que instituiu um novo regime fiscal no âmbito dos orçamentos fiscal e da Seguridade Social da União, em vigor por vinte exercícios financeiros.

No que toca à integralidade como um meio de concretizar a saúde em uma questão de cidadania, Pinheiro (2009) destaca que é necessário compreender sua operacionalização a partir de dois movimentos recíprocos a serem desenvolvidos pelos sujeitos implicados nos processos organizativos em saúde. A autora afirma que a integralidade se constitui à medida que obstáculos são superados e inovaçóes são implantadas no cotidiano dos serviços de saúde, nas relaçóes entre os níveis de gestão e entre estes e a sociedade.

É sabido que o atual modelo de gestão pública no SUS, não apenas no que tange à atenção primária, carece de agilidade, é burocrático, não reflete o compromisso social, tampouco a responsabilidade sanitária assumidos pelo Estado brasileiro na CF/1988. Contudo, inovar não pode e não deve ser transferir a responsabilidade pública governamental para organizaçóes sem fins lucrativos e/ou filantrópicas de direito privado.

Se, por um lado, implementar tais recomendaçóes pode aumentar a confiança dos mercados financeiros a curto prazo (em especial no contexto da crise sanitária), por outro, impede a concretização da integralidade como eixo prioritário da política nacional de saúde e distancia a realização da saúde do direito humano fundamental e universal. Como descrito por Azevedo e Silva (2020), assegurar a integralidade e a universalidade do SUS pressupóe reiterar, garantir e qualificar a gestão pública dos serviços, em especial aqueles que compóem a atenção primária em saúde.

A equidade apontada pela OMS como princípio básico para o desenvolvimento humano e a justiça social indica que a igualdade de direitos está alicerçada na ideia de justiça e reconhece que as desigualdades entre indivíduos e grupos demandam abordagens diversificadas como condição para a redução das diferenças existentes. Situação contrária à equidade é a iniquidade. Whitehead (1992) 
explica que iniquidade tem dimensão moral e ética, refere-se a diferenças que são desnecessárias, que se podem prevenir e evitar e, além disso, são consideradas injustas, uma vez que sua causa é examinada com base no contexto vivido no resto da sociedade.

O racismo, como fenômeno ideológico, engloba um conjunto de atitudes fundadas em preconceitos raciais, comportamentos discriminatórios, disposiçóes estruturais e práticas institucionalizadas que atribuem características negativas a determinados padróes de diversidade e significados sociais prejudiciais aos grupos que os detêm, resultando em desigualdade racial. Ele define as regras de convivência e organizaçáo social e, ao mesmo tempo, o modo como as instituiçóes se organizam e operam. No caso da população negra, as desigualdades de nascer, viver, adoecer e morrer são desnecessárias, poderiam ser prevenidas e evitadas se, e somente se, o racismo fosse devidamente reconhecido como determinante social da saúde e o seu enfrentamento assumido como prioritário dentro e fora dos serviços que compóem a rede SUS (Lopes, 2005a; Lopes e Quintiliano, 2007; Lopes, 2020).

\section{INIQUIDADES RACIAIS, RACISMO INSTITUCIONAL, COVID-19 E POPULAÇÃO NEGRA}

Desde a década de 1980 o movimento negro e o movimento de mulheres negras apontavam a necessidade de se dar visibilidade às desigualdades em saúde entre negros e brancos. Não de modo acidental, houve expressiva participaçáo destes movimentos na VIII Conferência Nacional de Saúde, em 1986, marco histórico da luta em defesa da saúde como direito humano fundamental, luta que persiste até hoje no processo de consolidação do SUS como política de um Estado democrático e de direito (Lopes e Werneck, 2009).

Os baixos níveis de escolaridade e renda, a baixa representatividade política e as restriçóes de acesso aos bens e aos serviços descritos pelo IBGE (2019) são, na verdade, evidências do racismo, que confere ausência de proteção e garantia de direitos, oportunidades desiguais, desigualdade na distribuição do poder, discriminação e injustiça à população negra. Como descrito por Almeida (2018), o racismo, ao definir o tecido social, apresenta-se como uma forma estratégica de garantir a apropriaçáo dos resultados positivos da produção de riquezas pelos segmentos sociorraciais privilegiados, ao mesmo tempo que ajuda a manter a fragmentação da distribuição destes resultados no seu interior.

A operação do racismo influencia as trajetórias individuais e coletivas; no setor saúde, influencia os indicadores de gestão, seja do ponto de vista da eficácia, da eficiência ou da efetividade, e, por consequência, os indicadores de saúde. Destarte, enfrentar o racismo dentro e fora do SUS é requisito para garantia e efetivação da saúde como direito individual e coletivo, expresso no Estatuto da Igualdade Racial - Lei Federal no 1.288, de 20 de julho de 2010 (Brasil, 2010), e na Política Nacional de Saúde Integral da População Negra - Portaria no 992 do Gabinete do Ministro da Saúde, de 13 de maio de 2009 (Brasil, 2009b).

Promover a equidade em saúde pressupóe visibilidade estatística. No Brasil, embora a Lei $\mathrm{n}^{-}$1.288/2010 e as portarias ministeriais no 992, de 13 de maio de 2009 (Política Nacional de Saúde Integral da População Negra - PNSIPN), e nº 344, de 1o de fevereiro de 2017, preconizem o uso da variável raça/cor como instrumento de gestão, na estratégia de vigilância da Covid-19, a variável só passou a constar das fichas de notificação em meados de abril, após grande pressão do movimento social, da comunidade acadêmica e de associaçóes profissionais, operadores do direito (Borges e Guimarães, 2020; Abrasco, 2020b; Covid-19..., 2020; Portal Geledés, 2020; SBMFC, 2020). 
Ao analisarem as notificaçóes de internação por Síndrome Respiratória Aguda Grave (SRAG) em unidades de saúde (públicas e privadas), Batista et al. (2020) constataram que as chances de morte de um paciente preto ou pardo analfabeto são 3,8 vezes maiores que um paciente branco com nível superior $(19,6 \%)$, confirmando as enormes disparidades no acesso e na qualidade do tratamento no Brasil. Os autores verificaram ainda que a proporção de óbitos em pacientes pretos e pardos foi maior que a observada em brancos, mesmo controlando por faixa etária, nível de escolaridade, e ainda que esta pessoa residisse em município com índice de desenvolvimento humano municipal elevado. Embora haja grande incompletude no preenchimento do quesito raça/cor (cerca de $30 \%$ dos casos notificados apresentam a informação sobre raça/cor como ignorada), os dados mostram que 55\% dos pacientes negros, hospitalizados com Covid-19 em estado grave, morreram em comparaçáo com $34 \%$ dos pacientes brancos. Este cenário reforça a tese de que o racismo institucional, manifesto na inação consciente das instituições públicas governamentais ante as necessidades da população negra, materializa-se, de forma gritante, nas altas taxas de mortalidade observadas para o grupo no contexto da pandemia da Covid-19 (Goes et al., 2020; Santos et al., 2020; Oliveira et al., 2020; Silva, 2020; Xavier, 2020; Varga et al., 2020).

Sabe-se que as taxas de mortalidade envolvem uma combinação de fatores, tais como oportunidade e condiçóes de diagnóstico (incluindo acesso aos testes), assistência aos sintomáticos (com tempestividade e qualidade), bem como as capacidades de prevenção e controle da transmissão do vírus e da doença por meio do conjunto de medidas náo farmacológicas, e isso tudo se reflete nos registros de casos e óbitos.

Como descrito pelo Boletim Observatório Covid-19 (Fiocruz, 2020), se, por um lado, parte expressiva da população brasileira acometida pela Covid-19 teve acesso a serviços de saúde em diferentes níveis de complexidade, por outro, a pandemia expôs fragilidades desse sistema, acumuladas em função do subfinanciamento e graves problemas de gestão. $\mathrm{O}$ diagnóstico inicial da capacidade instalada no país para o atendimento de pacientes graves, que demandam estruturas de cuidado complexas, estampou grandes desigualdades entre as regiôes e forte concentração de recursos voltados para o setor de saúde suplementar em áreas específicas, com proporçóes elevadas de beneficiários de planos de saúde.

De acordo com a Fundação Oswaldo Cruz (Fiocruz), mostrou-se gritante a diferença na disponibilidade de leitos de Unidade de Terapia Intensiva (UTI) para atender 74\% de cidadãos brasileiros que dependem, exclusivamente, dos serviços que compóem a rede SUS para receber tratamento médico, comparada aos $26 \%$ que possuem planos de saúde. Importante notar que, de acordo com a Pesquisa Nacional de Saúde (IBGE, 2015), a população SUS dependente é prioritariamente negra e do sexo feminino.

Ao estudarem os dados disponíveis no Sistema de Mortalidade do Município de São Paulo de óbitos por Covid-19 até 31 de julho de 2020, pesquisadores do Instituto Pólis (2020) observaram que a taxa de mortalidade padronizada de pessoas brancas era de 115 óbitos a cada 100 mil habitantes e a de pessoas negras, 172 mortes a cada 100 mil habitantes, revelando uma diferença para mais de 57 pontos percentuais (p.p.) entre negros e brancos. O instituto afirma que a taxa padronizada de mortalidade entre pretos e pardos (172 mortes/100 mil habitantes) indica que, no município de São Paulo, seria esperado um total de 4.091 óbitos entre pessoas negras caso suas condiçóes de vida e sua pirâmide etária fossem iguais às da cidade como um todo. Entretanto, foram registradas 5.312 mortes 
de pessoas pretas e pardas até 31 de julho: uma sobremortalidade de 1.221 vítimas (29,8\% a mais do que se esperaria). A mesma padronização aponta que, para aquele período, seriam esperados 11.110 óbitos de pessoas brancas, contudo, foram registradas 9.616 mortes, ou seja, 13,4\% a menos que o esperado para o grupo.

Os resultados do estudo também evidenciaram desigualdades inter e intragrupos de sexo e raça/cor. A taxa padronizada de mortalidade para homens brancos foi de 157 óbitos/100 mil habitantes. Neste grupo, houve um acréscimo de 17,6\% na relação óbitos esperados e observados. Já entre os homens negros a taxa padronizada foi de 250 óbitos/100 mil habitantes, com um aumento de $88 \%$ entre os óbitos esperados e os observados. Para as mulheres negras, a taxa padronizada foi de 140 óbitos/100 mil habitantes e a sobremortalidade de 3,2\%. Os pesquisadores ainda destacam que, embora todas as taxas tenham crescido durante o período analisado, o movimento ascendente da curva de mortalidade de homens, com influência negativa nitidamente mais intensa entre homens negros, reflete maior impacto relativo da pandemia neste grupo.

Nas instituiçóes de saúde públicas ou privadas, a pandemia da Covid-19 deixa nítido o que descreve Werneck (2016, p. 542): “o racismo institucional é um mecanismo performativo, capaz de gerar e legitimar condutas excludentes, tanto no que se refere a formas de governo quanto de accountability". Para a autora, a efetividade da expressão institucionalizada do racismo é dada pelo estabelecimento de "barreiras amplas - ou precisamente singulares - que permitem a realizaçáo de privilégio para uns, em detrimento de outros, em toda sua ampla diversidade”.

Retomar o exercício do controle social exigindo respostas eficientes, eficazes e tempestivas do poder público ante as demandas sociais é urgente. A defesa do SUS, em especial, mas não somente, pela população negra, continua sendo uma questão política, de direito e de dignidade e justiça social. Está assentada na defesa das vidas a necessidade de converter o SUS em um sistema, efetivamente, antirracista.

\section{EM DEFESA DO SUS: CONTRA O RACISMO E PELAS VIDAS}

Como descrito por Schucman (2010), se no Brasil o fenômeno do racismo é atualizado, perpetuado e legitimado pela ideia de raça, logo, é através desta categoria política que a luta antirracista deve ser articulada.

A raça é um importante determinante das relaçôes sociais e do acesso aos cuidados de saúde, o que não é necessariamente congruente com a etnia. Diferentemente de outros países onde a raça é definida como ancestralidade, no Brasil prevalece uma classificação fenotípica, e quanto mais escura a pele, maior a incidência de racismo e piores os indicadores de saúde. A cor da pele é, portanto, a variável utilizada para a análise do racismo estrutural e para a formulação e implementação de políticas de saúde que abordem o tema (Lopes e Malachias, 2001; Lopes, 2005a; 2005b; Pilecco et al., 2020).

Como expresso na PNSIPN (Brasil, 2009b), reiterado por Batista e Barros (2017) e discutido ao longo deste ensaio, raça/cor, classe social, gênero e geração são estruturantes em nossa sociedade, interferindo nos desfechos da saúde, da doença, do cuidado e das mortes.

Utilizar essas evidências como subsídios para garantir avançar na pesquisa, aprimorar a vigilância e a assistência, tornar eficiente a gestão e estimular o controle social e a eficácia à governança em saúde é o que nos permitirá converter o SUS em um efetivo mecanismo de justiça social. Por esse 
ângulo, é necessário que todo o sistema (gestores, provedores e trabalhadores) se comprometa com respostas a algumas questóes básicas, tais como: qual é a origem das brechas nos indicadores de saúde; por que estas brechas são sempre em detrimento de grupos sociais subjugados em seus direitos; quais são os fatores condicionantes de natureza socioeconômica (nível de renda e tipo de ocupação, lugar e condição de residência, estilos de vida, qualidade e acesso à informação e à educação formal) que influenciam a distribuição das doenças, agravos e mortes.

Ao se analisar o padrão desigual de distribuição das doenças, agravos e mortes nos diferentes grupos populacionais, o elemento de comparação é feito sempre com referência aos indicadores apresentados para a população branca (dado que o padrão adotado para estes é o aceitável/desejável)? Se a resposta for sim, isso não basta. As comparaçóes intragrupos também devem ser realizadas, caso contrário, para além de partir do falso pressuposto de que o SUS já está se apresentando da melhor forma para a população branca, ainda corre-se o risco de deixar para trás quem, historicamente, tem sido excluído entre os excluídos. Reconhecer a existência e a persistência do racismo estrutural, bem como seus efeitos diferenciados em cada segmento da população negra, é passo fundamental para compreender as dimensóes individual e também coletiva da vulnerabilidade vivenciada pelo grupo.

Avançando para a dimensão programática da vulnerabilidade, é preciso questionar quais são os fatores internos ao setor da saúde que, associados aos determinantes socioeconômicos, políticos, ambientais e socioculturais, se analisados com a devida atençâo, deixarão evidentes o racismo impregnado no setor; sua interferência no acesso e possíveis influências na naturalização de processos e procedimentos discriminatórios; comportamentos e atitudes cruéis e degradantes, seja na gestão ou na assistência.

Para Jones (2000), o racismo institucionalizado é uma inaçáo evidente diante da necessidade; por isso é tão importante verificar também se as estruturas comparativas apontam o passo seguinte ou se estão restritas à descrição das diferenças na distribuição de doenças, agravos e mortes entre os grupos. É necessário saber se existe uma dependência excessiva de dados quantitativos - incidência, prevalência, mortalidade, carga de doenças e outras condiçóes adversas de saúde - que leva os atores políticos a desprezar variáveis contextuais (ou acreditar que a redução das desigualdades entre grupos anula a necessidade de compreensão sobre os processos de intervençáo para a promoçáo da saúde e da equidade, e enfrentamento ao racismo).

Por fim, à guisa de conclusão, para se constituir, efetivamente, em uma política antirracista, espera-se do SUS respostas abrangentes, multidimensionais, transdisciplinares e intersetoriais, com participação efetiva da população, tal qual descrito na CF/1998, na Lei Orgânica do SUS (Lei $\mathrm{n}^{\circ}$ 8.080, de 19 de setembro de 1990) e na Lei no 8.142, de 8 de dezembro de 1990; do mesmo modo que se espera adequação ao preconizado no Estatuto da Igualdade Racial (Lei no 12.288, de 20 de julho de 2010) e regulamentado pela PNSIPN.

Neste momento tenho um sonho. Sonho em fazer parte de uma sociedade desenvolvida; que não coaduna com políticas de morte; desnaturaliza o racismo e qualquer outra forma de hierarquização social; defende a democracia; valoriza e se importa com todas as vidas; e que enxerga o SUS como uma possibilidade real de mudança. E, como sonhar não é suficiente, ainda que seja coletivamente, sigamos em ação e na luta. 


\section{REFERÊNCIAS}

ABRASCO - ASSOCIAÇÃO BRASILEIRA DE SAÚDE COLETIVA. A populaçáo negra e o direito à saúde: risco de negros morrerem por Covid-19 é 62\% maior se comparado aos brancos. 2020a. Disponível em: <https://www.abrasco.org.br/site/noticias/especial-coronavirus/a-populacao-negra-e-odireito-a-saude-risco-de-negros-morrerem-por-covid-19-e-62-maior-se-comparado-aos-brancos/47741/> .

. Carta ao Ministério da Saúde sobre a informaçáo raça/cor nos sistemas de informaçáo da Covid-19. 2020b. Disponível em: <https:/www.abrasco.org.br/site/noticias/posicionamentosoficiais-abrasco/carta-ao-ministerio-da-saude-sobre-a-informacao-raca-cor-nos-sistemas-de-informacaoda-covid-19/47320/>.

Fortalecer o SUS, em defesa da democracia e da vida. 2020c. Disponivel em: <https:// www.abrasco.org.br/site/publicacoes/fortalecer-o-sus-em-defesa-da-democracia-e-da-vida/53604/>. ALMEIDA, Silvio. O que é racismo estrutural? Belo Horizonte: Letramento, 2018.

AZEVEDO e SILVA, Gulnar. Em defesa do SUS e pelo fortalecimento da atenção primária à saúde. Abrasco, 2020. Disponível em: <https://www.abrasco.org.br/site/noticias/opiniao/em-defesado-sus-e-pelo-fortalecimento-da-atencao-primaria-a-saude-artigo-de-gulnar-azevedo-e-silva/53655/>.

BATISTA, Amanda et al. Análise socioeconômica da taxa de letalidade da Covid-19 no Brasil. Rio de Janeiro: NOIS, 2020. (Nota Técnica, n. 11). Disponível em: <https://ponte.org/wp-content/ uploads/2020/05/NT11-An\%C3\%A1lise-descritiva-dos-casos-de-COVID-19.pdf>. Acesso em: 30 ago. 2020.

BATISTA, Luis Eduardo; BARROS, Sônia. Enfrentando o racismo nos serviços de saúde. Cadernos de Saúde Pública, Rio de Janeiro, v. 33, n. 13, 2017. Disponível em: <http://cadernos.ensp.fiocruz. br/csp/artigo/81/enfrentando-o-racismo-nos-servicos-de-saude>. Acesso em: 2 nov. 2020.

BORGES, Pedro; GUIMARĀES, Juca. Movimento negro protocolou pedido no Ministério da Saúde no dia 8 de abril; Dados nos EUA mostram que a maior parte dos atingidos pela Covid-19 são negros. Alma Preta, 10 abr. 2020. Disponível em: <https://almapreta.com/editorias/realidade/ covid-19-ministerio-da-saude-divulgara-dados-de-infectados-por-raca-cor>.

BRASIL. Constituição da República Federativa do Brasil de 1988. Brasília, 1988. Disponível em: <http:/www.planalto.gov.br/ccivil_03/constituicao/constituicao.htm>.

. Ministério da Saúde. Secretaria de Vigilância em Saúde. Departamento de Análise de Situação em Saúde. Saúde Brasil 2006: uma análise da situação de saúde no Brasil. Brasília: Ministério da Saúde, 2006.

. Ministério da Saúde. O SUS de A a Z: garantindo saúde nos municípios. 3. ed. Brasília, 2009a.

. Ministério da Saúde. Gabinete do Ministro. Portaria no 992, de 13 de maio de 2009. Política Nacional de Saúde Integral da Populaçáo Negra: uma política do SUS. Brasília: Ministério da Saúde, 2009b. Disponível em: <http://bvsms.saude.gov.br/bvs/saudelegis/gm/2009/ prt0992_13_05_2009.html>.

. Presidência da República. Casa Civil. Subchefia para Assuntos Jurídicos. Lei noํ⒓288, de 20 de julho de 2010. Estatuto da Igualdade Racial. 2010. Disponível em: <http://www. planalto.gov.br/ccivil_03/_Ato2007-2010/2010/Lei/L12288.htm\#:- :text=1o\%20Esta\%20Lei\%20 institui,demais\%20formas\%20de\%20intoler\%C3\%A2ncia\%20\%C3\%A9tnica>. 
Ministério da Saúde. Gabinete do Ministro. Portaria no 344, de 1o de fevereiro de 2017. Dispóe sobre o preenchimento do quesito raça/cor nos formulários dos sistemas de informação em saúde. 2017. Disponível em: <https://bvsms.saude.gov.br/bvs/saudelegis/gm/2017/prt0344_01_02_2017.html>. COVID-19: registro de raça e de cor deve constar em formulário de paciente. Correio Brasiliense, 21 jul. 2020. Disponível em: <https://www.correiobraziliense.com.br/app/noticia/cidades/2020/07/21/ interna_cidadesdf,873982/covid-19-registro-de-raca-e-de-cor-deve-constar-em-formulario-de-paci.shtml>.

FIOCRUZ - FUNDAÇÃO OSWALDO CRUZ. Boletim Observatório Covid-19 após 6 meses de pandemia no Brasil. Boletim Observatório Covid-19. 2020. Disponivel em: <https://portal. fiocruz.br/sites/portal.fiocruz.br/files/documentos/boletim_covid_6meses.pdf>.

FONTELES, Samuel Sales. Direitos fundamentais. 2. ed. Salvador: Juspodivm, 2016. 9 p.

GARBOIS, Júlia Arêas; SODRE, Francis; DALBELLO-ARAUJO, Maristela. Da noção de determinação social à de determinantes sociais da saúde. Saúde Debate, v. 41, n. 112, p. 63-76, mar. 2017. Disponível em: <http://www.scielo.br/scielo.php?script=sci_arttext\&pid=S0103$11042017000100063 \&$ lng=en\&nrm=iso > . Acesso em: 3 set. 2020.

GOES, Emanuelle Freitas; RAMOS, Dandara Oliveira; FERREIRA, Andrea Jaqueline Fortes. Desigualdades raciais em saúde e a pandemia da Covid-19. Trabalho, Educaçáo e Saúde, Rio de Janeiro, v. 18, n. 3, 2020.

IBGE - INSTITUTO BRASILEIRO DE GEOGRAFIA E ESTATÍSTICA. Pesquisa Nacional de Saúde 2013: acesso e utilização dos serviços de saúde, acidentes e violência. Brasil, Grandes Regióes e Unidades da Federação. Rio de Janeiro: IBGE, 2015. 100 p.

. Informativo IBGE sobre desigualdades sociais por cor ou raça no Brasil. Estudos e Pesquisas - Informação Demográfica e Socioeconômica, n. 41, nov. 2019.

INSTITUTO PÓLIS. Raça e Covid no município de São Paulo. São Paulo: Instituto Polis, 2020. Disponível em: <https://polis.org.br/estudos/raca-e-covid-no-msp/>.

JONES, C. P. Levels of racism: a theoretic framework and a gardener's tale. Am J Public Health, v. 90, n. 8, p. 1212-1215, 2000.

LOPES, Fernanda. Experiências desiguais ao nascer, viver, adoecer e morrer: tópicos em saúde da população negra. In: BATISTA, L. E.; KALCKMANN, S. (Org.). Seminário Saúde da Populaçáo Negra no Estado de São Paulo 2004. São Paulo: Instituto de Saúde, 2005a, p. 53-102.

- Para além da barreira dos números: desigualdades raciais e saúde. Caderno de Saúde Pública, Rio de Janeiro, v. 21, n. 5, p. 1595-1601, 2005 b.

Desigualdades em saúde no Brasil: panorama e desafios. Canal do Centro de Integração de Dados e Conhecimentos em Saúde da Fundação Oswaldo Cruz (CIDACS Fiocruz) no Youtube, 2020. Disponível em: <https://www.youtube.com/watch?v=x9s7yGYOHcg>. Acesso em: 30 ago. 2020.

LOPES, Fernanda; MALACHIAS, Rosangela. Assumir a diferença para promover a igualdade: a importância do quesito cor na investigação epidemiológica. Boletim Epidemiológico de AIDS do PE-DST/AIDS, n. 2, ano XIX, out. 2001.

LOPES, Fernanda; QUINTILIANO, Rachel. Racismo institucional e o direito humano à saúde. Democracia Viva, n. 34, p. 8-16, 2007. 
LOPES, Fernanda; WERNECK, Jurema. Saúde da população negra: da conceituação às políticas públicas de direito. In: WERNECK, J. (Org.). Mulheres negras: um olhar sobre as lutas sociais e as políticas públicas no Brasil. Rio de Janeiro: Criola, 2009. p. 5-23. Disponível em: <http://www.bibliotecadigital. abong.org.br/bitstream/handle/11465/886/81.pdf?sequence=1\&isAllowed=y>. Acesso em: 23 ago. 2020 .

OLIVEIRA, Roberta Gondim de et al. Desigualdades raciais e a morte como horizonte: consideraçóes sobre a COVID-19 e o racismo estrutural. Cadernos de Saúde Pública, v. 36, n. 9, 2020. Disponível em: <https://doi.org/10.1590/0102-311X00150120>. Acesso em: 2 nov. 2020.

PILECCO, Flávia et al. Addressing racial inequalities in a pandemic: data limitations and a call for critical analyses. Lancet Glob Health 2020 Published Online September 15, 2020. Disponível em: <https:/www.thelancet.com/journals/langlo/article/PIIS2214-109X(20)30360-0/fulltext>.

PINHEIRO, Roseni. Integralidade. Dicionário da Educação Profissional em Saúde. 2009. Disponível em: <http:/www.epsjv.fiocruz.br/dicionario/verbetes/intsau.html>.

PORTAL GELEDÉS. Nota da coalisão negra por direitos sobre Covid-19. Mar. 2020. Disponível em: <https:/www.geledes.org.br/nota-da-coalizacao-negra-por-direitos-sobre-o-covid-19/>.

SANTOS, Marcia Pereira Alves et al. População negra e Covid-19: reflexóes sobre racismo e saúde. Estudos Avançados, v. 34, n. 99, p. 225-244, ago. 2020. Disponível em: <http://www.scielo. $\mathrm{br} /$ scielo.php?script=sci_arttext\&pid=S0103-40142020000200225\&lng=en\&nrm=iso >. Acesso em: 30 ago. 2020.

SBMFC - SOCIEDADE BRASILEIRA DE MEDICINA DE FAMÍLIA E COMUNIDADE. Grupo de Trabalho Saúde da População Negra. Manifestação sobre ausência de dados da COVID-19 desagregados por raça/cor. 2020. Disponível em: <https://www.sbmfc.org.br/noticias/gt-de-saude-dapopulacao-negra-manifestacao-sobre-ausencia-de-dados-da-covid-19-desagregados-por-raca-cor/> .

SCHUCMAN, Lia Vainer. Racismo e antirracismo: a categoria raça em questão. Revista Psicologia Política, São Paulo, v. 10, n. 19, p. 41-55, jan. 2010 . Disponível em: <http://pepsic.bvsalud.org/ scielo.php?script=sci_arttext\&pid=S1519-549X2010000100005\&lng=pt\&nrm=iso $>$. Acesso em: 2 nov. 2020.

SILVA, Alexandre. Racismo e Saúde: COVID-19 entre a população negra. Fundo de População das Naçóes Unidas. Podcast. Episódio 7. 2020. Disponível em: <https://brazil.unfpa.org/pt-br/ news $\%$ E2\% $\% 0 \%$ Cprecisamos-fazer-um-enfrentamento-rever-planos-e-discutir-o-racismo-nestemomento-da-pandemia $\%$ E2\%80\%9D>.

SOLAR, O.; Irwin, A. A conceptual framework for action on the social determinants of health. Social Determinants of Health Discussion Paper 2 (Policy and Practice). 2010. Disponível em: <https://www.who.int/sdhconference/resources/ConceptualframeworkforactiononSDH_eng.pdf>.

VARGA, István van Deursen et al. Um retrato das desigualdades étnico-raciais na saúde. In: STEFANO, Daniela; MENDONÇA, Maria Lúcia (Org.). Direitos humanos no Brasil, 2020: relatório da Rede Social de Justiça e Direitos Humanos. São Paulo: Outras Expressões, 2020. 316 p.

WERNECK, Jurema. Racismo institucional e saúde da população negra. Saude e Sociedade, São Paulo, v. 25, n. 3, p. 535-549, set. 2016. Disponível em: <http://www.scielo.br/scielo.php?script=sci_ arttext\&pid=S0104-12902016000300535\&lng=en\&nrm=iso >. Acesso em: 31 jan. 2021. 
WHITEHEAD, Margaret. The concepts and principles of equity and health. International Journal of Health Services, v. 22, n. 3, p. 429-445, 1992.

XAVIER, Lucia. O coronavírus não tem nada de democrático. Ele tem preferências, e os negros são um dos grupos preferidos dele. Gênero e Número. 2020. Disponível em: <http://www.generonumero. media/entrevista-o-coronavirus-nao-tem-nada-de-democratico-ele-tem-preferencias-e-os-negros-saoum-dos-grupos-preferidos-dele/>. 
